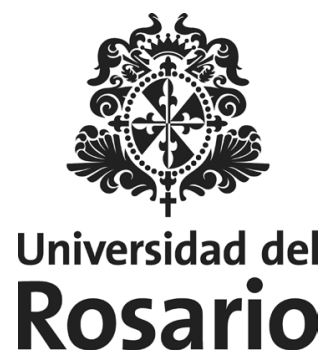





\section{Cartas imaginarias a Freud y otros ensayos}


Fergusson, Alberto

Cartas imaginarias a Freud y otros ensayos / Alberto Fergusson. - Bogotá : Editorial Universidad del Rosario, Escuela de Medicina y Ciencias de la Salud, 2015.

xiii, 204 páginas. - (Colección Textos de Medicina y Ciencias de la Salud)

ISBN: 978-958-738-590-8 (rústica)

ISBN: 978-958-738-591-5 (digital)

Freud, Sigmund, 1856-1939 - Crítica e interpretación / Psiquiatría / Psicoanálisis / Sociología / Inteligencia / I.

Título / II. Serie.

150.1952

$\operatorname{SCDD} 20$

Catalogación en la fuente - Universidad del Rosario. Biblioteca 


\title{
Cartas imaginarias a Freud y otros ensayos
}

\author{
Alberto Fergusson
}




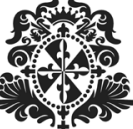

Colección Textos de Medicina y Ciencias de la Salud

(C) Editorial Universidad del Rosario

(C) Universidad del Rosario, Escuela de Medicina y Ciencias de la Salud

(c) Alberto Fergusson

(C) Miguel Gutiérrez-Peláez, por el prólogo

Editorial Universidad del Rosario Carrera 7 No $12 \mathrm{~B}-41$, oficina 501

Teléfono 2970200

editorial.urosario.edu.co

Primera edición: Bogotá D.C., junio de 2015

ISBN: 978-958-738-590-8 (rústica)

ISBN: 978-958-738-591-5 (digital)

Coordinación editorial: Editorial Universidad del Rosario

Revisión de la edición: Naysla Yahuar Pacheco

Diseño de cubierta: Miguel Ramírez, Kilka DG

Diagramación: Margoth de Olivos S.A.S.

Impresión: Xpress Estudio Gráfico y Digital S.A.

Impreso y hecho en Colombia

Printed and made in Colombia

Todos los derechos reservados. Esta obra no puede ser reproducida sin el permiso previo por escrito de la Editorial Universidad del Rosario. 


\section{Contenido}

PRÓLOGO ...................................................................................... ix

Miguel Gutiérrez-Peláez

INTRODUCCIÓN

xiii

EL INTERÉS DEL PSICOANÁLISIS PARA LA SOCIOLOGÍA

1

CONSIDERACIONES ACERCA DE ALGUNOS ASPECTOS

DE LA INVESTIGACIÓN PSICOANALÍTICA

5

ELABORACIÓN DEL CONCEPTO DE SUBLIMACIÓN A PARTIR DEL

PENSAMIENTO DE FREUD

CARTA IMAGINARIA No. 1.

SOBRE LA INCONSCIENCIA DE LO REPRESOR

ATENCIÓN FLOTANTE E INTERPRETACIÓN

(SU RELACIÓN CON LOS SENTIMIENTOS MORALES DEL ANALISTA)........

LA TRANSFERENCIA Y EL PRECONSCIENTE DINÁMICO

EN LA RELACIÓN PSICOANALÍTICA

CARTA IMAGinaria No. 2.

SOBRE LOS DERIVADOS Y LOS REGISTROS MENTALES

CARTA IMAGINARIA No. 3.

SOBRE LA NECESIDAD DE DIFERENCIAR EL PUNTO DE VISTA

SISTÉMICO DEL PUNTO DE VISTA TÓPICO 
CARTA IMAGINARIA No. 4.

El AUTOPSICOANÁLISIS

LA LITERATURA CONTINÚA ANTICIPANDO AL PSICOANÁLISIS.

A PRopósito de la novela IRENE DE Jorge EliéCER PARDo ...........

EL CONSUMO DE DROGAS, LOS AFECTOS Y EL CUERPO........................... 103

LA INDUSTRIA DEL PLACER: (EL PLENO PLACER NARCISISTA)................ 109 Alberto Fergusson y Victoria Peralta

LA ESTUPIDEZ. OTRA VÍA REGIA AL INCONSCIENTE PSÍQUICO

123

¿QUÉ ES ESTAR EN FORMA PARA PSICOANALIZAR? AlgunOS ASPECTOS POCO ESTUDIADOS DE LA CAPACIDAD ANALÍTICA

LA TÉCNICA DEL AUTOANÁLISIS ACOMPAÑADO (A.U.A.C.) Y

LA TEORÍA DE LA PSICOSIS ENTENDIDA COMO DESTRUCCIÓN

Y DESCOMPOSICIÓN PSICOLÓGICA (D.D.P.)........................................... 157

LA PARADOJA DE LAS RELACIONES HUMANAS ……................................. 179

CARTA IMAginaria A Freud No. 5.

REPRESIÓN DEL PSICOANÁLISIS ........................................................... 185 


\section{Prólogo}

A lo largo de su vida, Sigmund Freud mantuvo una correspondencia constante con colegas, familiares, amigos y pacientes, que ha sido fundamental para entender su pensamiento y comprender cómo se construyó esa nueva ciencia llamada psicoanálisis. No cabe duda de que el principal intercambio epistolar fue el que sostuvo en su juventud con Wilhelm Fliess, aquel amigo de la juventud con quien desarrolló su autoanálisis, por ser el más estudiado en relación con el psicoanálisis; aunque no menos importante es la correspondencia con Ferenczi, Jung, Jones y Abraham; las hermosas cartas dirigidas a sus hijos y a su esposa Martha Bernays; las innumerables cartas que cruzó con personajes como Gustav Mahler y Albert Einstein, al igual que con pacientes y con personas interesadas en el psicoanálisis y otras que encontraban en él una inspiración vital para la puesta en marcha de movimientos que transformarían el mundo (como las que recibió del joven y entusiasta pintor español Salvador Dalí).

Lo que aquí resulta novedoso es que al inmenso historial de cartas que poblaron la vida Freud se sumen otras, pero no porque hayan sido publicadas una nuevas que hasta ahora se desconocían, sino porque han sido escritas en las postrimerías del siglo XX y los primeros años del siglo XXI, más de setenta años después de su muerte. Este hecho no es simplemente un ejercicio literario, ni tampoco una vía para adular o rendir tributo a Freud; es más bien un brillante recurso del cual se sirve para desplegar su pensamiento, para, en un diálogo profundo con Freud, revelar los aspectos más destacados y controversiales de la teoría freudiana y dejar ver el modo singular mediante el cual se ha apropiado de ella.

En 2012, en el seno de la Escuela de Medicina y Ciencias de la Salud de la Universidad del Rosario, Alberto Fergusson y yo creamos un grupo de estudio 
e investigación de psicoanálisis, que ha evolucionado al Instituto de Investigación Psicosocial, y que nos ha permitido conversar extensamente de nuestros intereses comunes sobre los orígenes del movimiento psicoanalítico y sobre ese crisol en el que hervían la ciencia, el arte, la política, la filosofía y la literatura que era la Viena de finales del siglo XIX y comienzos del XX. Hemos conversado también sobre cómo, con el auge del nazismo, que llevó al exilio a la gran parte de los psicoanalistas, Freud incluido, el psicoanálisis fue en gran medida reprimido (como bien lo expuso Russell Jacoby en su libro The Repression of Psychoanalysis).

Los psicoanalistas vieneses (como los de Budapest, Berlín y otros países de Europa), sobre los que recaían varios estigmas tanto en Europa como en América (eran en su mayoría judíos, de izquierda y, como si fuera poco, ¡psicoanalistas!), se vieron obligados a moderar sus posturas para lograr ser acogidos por la cultura propia de los países a los que llegaban, moderación que provocó no pocas pérdidas para el psicoanálisis. Por eso pienso este libro no como un retorno a la Viena de Freud, sino como una contribución decidida al levantamiento de la represión de ese psicoanálisis, del cual aún no conocemos su alcance definitivo. Y con ese psicoanálisis dialoga Alberto Fergusson; son esas las premisas que interroga, con las que trabaja y a las que hemos querido, dentro de nuestro grupo de estudio, sumar otros interlocutores.

Las cinco cartas imaginarias a Freud recogidas en este libro son su columna vertebral y los efectos que producirán en la comunidad psicoanalítica están aún por verse. Pero las cartas no agotan los aportes de esta obra. Alberto Fergusson, médico, psiquiatra y psicoanalista, tiene toda una historia vital dedicada al estudio y el tratamiento de pacientes psicóticos. En los años ochenta creó el Instituto de Autorrehabilitación Acompañada, inspirado en las premisas del freudomarxismo de la Escuela de Frankfurt y en el mal llamado "movimiento antipsiquiátrico" (mal llamado en la medida en que no se opone a la psiquiatría, sino más bien a una mala práctica psiquiátrica) y en los trabajos y experiencias de Laing, Cooper, Basaglia y Szasz. La materialización de los conceptos del Instituto se produjo en una singular experiencia denominada Fungrata, pero conocida en el mundo académico y profesional como "La granja". Esa institución, pionera en nuestro país, sigue produciendo asombro en varias partes del mundo por haber llegado, desde ya hace décadas, adonde muchos otros dispositivos dedicados a la intervención psicosocial con pacientes psicóticos hoy aspiran llegar. 
Alberto Fergusson ha hecho excepcionales aportes tendientes a eliminar el estigma de la psicosis y ha tenido esa sensibilidad fundamental necesaria en todo clínico: dejarse enseñar por la locura. En esta línea, el capítulo titulado "La técnica del autoanálisis acompañado (A.u.A.c.) y la teoría de la psicosis entendida como destrucción y descomposición psicológica (D.D.P.)” presenta aspectos centrales de cómo los años de estudio y el tratamiento de pacientes graves le han permitido forjar una teoría propia sobre el funcionamiento de la psicosis. Como testimonio del Instituto de Autorrehabilitación Acompañada y modelo que creó, implantó en experiencias prácticas y denominó precisamente "autorrehabilitación acompañada", se publica simultáneamente otro libro titulado Accompanied Selfrehabilitation.

Alberto Fergusson, al igual que Freud, es ante todo un humanista y sabe que cada médico y cada estudioso de la mente humana no extrae su conocimiento únicamente de los tratados de medicina y de los artículos publicados en revistas indexadas, sino también de los artistas y escritores, esos sujetos excepcionales que han llegado a las profundidades del alma humana y en su descenso han logrado conquistas a las que el psicoanálisis solo ha podido llegar después de un arduo trabajo. Por eso la presencia del arte en los capítulos "Elaboración del concepto de sublimación a partir del pensamiento de Freud" y "La literatura continúa anticipando al psicoanálisis. A propósito de la novela Irene de Jorge Eliécer Pardo", es un ingrediente imprescindible de la minuta de este libro.

Por otro lado, el título de algunos capítulos, como "La industria del placer: (El pleno placer narcisista)" y "La estupidez. Otra vía regia al inconsciente psíquico", anticipan al lector la pluma original, mordaz y aguda de Alberto Fergusson, que hacen de este estudio una producción inédita (incluso diríamos cierta desfachatez, esa que le permite contarle a Freud, en una de sus cartas, el asesinato de Guillermo Cano). Otros, como "¿Qué es estar en forma para psicoanalizar? Algunos aspectos poco estudiados de la capacidad analítica”; "Consideraciones acerca de algunos aspectos de la investigación psicoanalítica" y "La transferencia y el preconsciente dinámico en la relación psicoanalítica", recogen su interés y sus aportes a la teoría y técnica psicoanalítica, así como su entusiasmo por la formación de psicoanalistas.

Durante años Fergusson ha trabajado en la formación de estudiantes de psicología, de medicina y de otras profesiones en distintas universidades 
colombianas, y en los últimos años con los estudiantes del Programa de Psicología de la Universidad del Rosario, acercándolos a su modo particular y fértil de comprender los avatares de las pulsiones humanas.

Cabe resaltar que por los comentarios de psicoanalistas colombianos -algunos de ellos pioneros del movimiento psicoanalítico en Colombia- a las presentaciones de los escritos aquí incluidos, este libro representa además un documento histórico. Los escritos recopilados en esta edición se constituyen en la bitácora de viaje de un psicoanalista a las profundidades de la teoría psicoanalítica y de la mente humana. No solo es un compendio de estudios rigurosos, originales, impecablemente escritos, con aportes originales (pocas veces nos encontramos con ensayos que lean con tal precisión los estudios metapsicológicos de Freud), sino también un documento necesario e imprescindible para el pensamiento psicoanalítico de nuestro país y, en general, para todo el movimiento psicoanalítico.

Comentaba al inicio de este prólogo que Freud tuvo un séquito de interlocutores destacados con quienes intercambió cartas a lo largo de su vida. No hay duda que Sigmund Freud hubiera considerado a Alberto Fergusson un corresponsal a la altura. No hay duda de que le hubiera encantado asumir el reto de responder las cartas aquí publicadas y que hubieran sido para él un gran estímulo para continuar su interminable investigación sobre los laberintos de la mente humana. Esas respuestas, de haber existido, habrían sido auténticos cimientos de la doctrina freudiana, aportes primordiales para el pensamiento psicoanalítico. Por ahora no contamos con ellas y por fortuna eso no significa que el diálogo haya terminado. En eso radica la maravilla de este libro, pues cada lector que se anime a recorrer estas páginas será el depositario de ese diálogo imaginario con Freud. El efecto que produzca este libro en cada uno de ustedes, curiosos, estudiosos y entusiastas del pensamiento psicoanalítico, será la extensión de ese diálogo. Esperamos que nutran esta conversación, fundamental para el devenir futuro del psicoanálisis.

Miguel Gutiérrez-Peláez, PhD. Ubaté, Cundinamarca (Colombia), 2 de abril de 2015 


\section{Carta imaginaria a Freud No. 5 Represión del psicoanálisis ${ }^{* * * *}$}

Sopó, Colombia, abril de 2012

Apreciado profesor Freud:

Le escribo esta carta aprovechando que pronto atenderé una invitación que me hicieron los miembros del Grupo de Estudios Freudianos para asistir a su reunión anual en Londres en calidad de conferencista invitado. Sé que estoy despertando su incorregible curiosidad y alcanzo a imaginarme su sorpresa al enterarse de que existe dicho grupo conformado principalmente por psicoanalistas europeos y miembros de la Sociedad Británica de Psicoanálisis. Confío en que a medida que avance esta carta descubrirá los motivos que llevaron a la formación de dicho grupo y comprenderá la enorme importancia que tiene para mí acercarme a él. Cruzaré el océano en dirección inversa a la que usted recorrió cuando fue a la Universidad de Clark, con la esperanza de profundizar en temas que he tenido que abordar de manera bastante solitaria, plenamente consciente de lo que significa el Reino Unido tanto para usted como para el movimiento psicoanalítico. Por múltiples circunstancias históricas, geográficas y políticas, lo esencial de dicho movimiento siempre se pensó y se seguirá pensando en Londres.

\footnotetext{
* Esta es la quinta y última de una serie de cartas imaginarias dirigidas a Sigmund Freud enfocadas principalmente en lo que él llamó "la bruja”. En la presente carta, el autor explica de qué manera los cambios metapsicológicos generados por una adherencia a la regla fundamental pueden y deben llevar a un proceso psicoanalítico intrínsecamente interminable. Al final, el autor comparte con Freud algunas actualizaciones sobre recientes desarrollos en el movimiento psicológico y sus propias actividades con respecto a este movimiento.

** Artículo publicado en The Annual Bulletin of the British Psychoanalytical Society, Vol. 3. 2013.
} 
La carta de hoy es, sobre todo, un intento de identificar los principales cambios en la forma en la que funciona la mente, producidos por un psicoanálisis exitoso que debe llevar, en mi opinión, a un proceso interminable. Por lo tanto, el tema oficial del encuentro de Londres, "La terminación del análisis y sus vicisitudes", concuerda con los temas en esta carta. Pero en lugar de hablar de terminación intentaré describir de qué manera el psicoanálisis genera cambios irreversibles en la forma en que opera la mente y cómo, por extraño que parezca, es posible hablar de una comunidad de psicoanalizados. Finalmente, utilizaré el concepto de terminación en otro sentido para ilustrar cómo el psicoanálisis clásico ya no está de moda, por lo menos en el sentido que usted y los psicoanalistas de la segunda generación lo comenzaron a desarrollar antes de la llegada del nazismo. Y, con la intención de explicar lo anterior, le ofreceré una actualización de algunos aspectos del movimiento psicoanalítico y de mis propias actividades.

Han transcurrido más de 20 años desde que le escribí mi cuarta y última carta imaginaria $(1985,1987,1988$ a y 1989) y el ensayo titulado "La estupidez. Otra vía regia al inconsciente psíquico" (1992). En dichos escritos intenté avanzar en la comprensión de los cambios producidos durante el proceso psicoanalítico. Comenzaré resumiendo las conclusiones a las que llegué en mis cartas anteriores.

En mi primera carta fui muy crítico en relación con el último párrafo del primer capítulo de El yo y el ello. Recordemos la traducción de López Ballesteros (1923, p. 17):

Pero aún son más importantes las consecuencias que nuestro nuevo descubrimiento trae consigo para nuestra concepción de lo inconsciente. El punto de vista dinámico nos obligó a una primera rectificación; ahora, el conocimiento de la estructura anímica nos impone otra nueva. Reconocemos, pues, que lo Inc. no coincide con lo reprimido. Todo lo reprimido es inconsciente, pero no todo lo inconsciente es reprimido. También una parte del Yo, cuya amplitud nos es imposible fijar, puede ser inconsciente, y lo es seguramente. Y este Inc. del Yo no es latente en el sentido de lo Prec., pues si lo fuera no podría ser activado sin hacerse consciente, y su atracción a la consciencia no opondría tan grandes dificultades. Viéndonos así obligados a admitir un tercer Inc. no reprimido, hemos de confesar que la inconsciencia pierde importancia a nuestros ojos, convirtiéndose en una cualidad de múltiples sentidos 
que no permite deducir las amplias y exclusivas conclusiones que esperábamos. Sin embargo, no deberemos desatenderla, pues en último término, la cualidad de consciente o no consciente es la única luz que nos guía en las tinieblas de la psicología de las profundidades.

Afortunadamente, incluyó las palabras "sin embargo". Jamás entenderé qué le ocurría mientras escribía dicho párrafo. Para comenzar, no debió hablar de un tercer Inc. Usted dejó claramente planteado que dicha abreviación la utilizaría solamente cuando estuviera hablando del sentido topográfico-sistémico de la palabra inconsciente. Tal como lo describió recientemente Clifford York en un Festschrift para Pearl King, usted definió los tres sentidos de la palabra inconsciente en 1912 (York, 2001). La identificación de un nuevo sentido constituiría el cuarto, no un tercer sentido del Inc. Usted siempre reconoció que la palabra inconsciente tenía una gran polisemia y veía en ello una fortaleza del concepto, no una debilidad. En 1923, lo noto confundido y en medio de cierto desespero teórico. Comprendo bien en qué se fundamentaron sus preocupaciones, viéndose obligado a enfrentar el fascinante pero complejo problema de la inconsciencia de lo represor: ¿cómo puede la represión ser dinámicamente inconsciente al mismo tiempo que pertenece al sistema Pc-Cs? Lo invité a que aceptara que dicha inconsciencia era un ejemplo más del sentido dinámico de la palabra "inconsciente" y que quizás llegamos a nuestra primera represión en medio de un proceso de ensayo y error, en la medida en que la misma no puede ser exitosa si no es excluida a su vez de la consciencia, junto con lo reprimido.

En mi segunda carta me referí al tema de los derivados y los registros mentales, introduje los conceptos de "eventos psíquicos primarios y secundarios", y exploré la forma en la cual los derivados se pueden identificar en la práctica clínica. Sugerí que si aceptamos que tanto las pulsiones (triebs) como las ideas son procesos, entendemos que estas se pueden registrar en el Inc. o en el Pc-Cs, en diferentes momentos de dicho proceso. El estudio clínico de la estupidez sintomática de los llamados inteligentes me permitió precisar de qué manera se da el proceso: un instinto, un trieb, es un proceso a través del cual una "fuente somática" genera una carga (Drang) "psíquica” que busca un objeto para lograr su fin, que es la descarga. A nivel especulativo, podemos aceptar que al Drang se 
le opone una contracarga primaria que sería la represión primaria o primera represión. La contracarga primaria nunca habría permitido el ingreso del impulso al sistema $\mathrm{Pc}-\mathrm{Cs}$. El impulso reprimido y la represión primaria interactúan con el evento psíquico primario, el cual puede ser una representación mental de un evento externo o una fantasía, y forman el derivado primario. El derivado primario incluye lo reprimido y lo represor, y está registrado en el Pc-Cs. Por definición, no es solo una idea concreta: tiene "palabra" y la posibilidad de adquirir cualidad de consciencia y por lo tanto pugna por su descarga. Durante la adquisición de cualidad de consciencia y la posibilidad de verbalización, se integran la teoría y la práctica psicoanalíticas en la regla fundamental al convertirse esta última en la mejor vía conocida para detectar los derivados de lo reprimido y lo represor. El derivado primario y la represión secundaria, al estar nuevamente en el sistema Inc., interactúan con el evento psíquico secundario y forman los derivados secundarios, tales como los sueños, los síntomas y, para el analista práctico, la transferencia y la transferencia recíproca (contratransferencia), las cuales pueden o no darse en cada momento de la relación analítica. Profesor Freud, después de su muerte los conceptos de transferencia y contratransferencia se empezaron a volver sinónimo de la relación analítica, con lo cual tienden a desaparecer como conceptos, pues si algo es todo al mismo tiempo, termina no siendo nada (Fergusson, 1986).

En mi tercera carta traté de mostrar la necesidad de diferenciar el sentido tópico del sistémico en la palabra inconsciente, cosa que usted no estableció de manera clara. Le propuse que utilizáramos la letra " $t$ " o "s" después de Inc. o Pc-Cs para diferenciar dichos sentidos y evitar hablar de cosas como los contenidos del sistema Inc., un tema mejor discutido desde el punto de vista topográfico. Esta diferenciación ayuda a que el psicoanálisis se afirme en su propia topografía, la mente, y así evita el riesgo continuo de apropiarse de las topografías propias de la biología y/o la sociología. Ayuda también a que el psicoanálisis recupere plenamente el concepto científico de la mente, tan cuestionado hoy en día por las interpretaciones erróneas de los grandes avances de la neurociencia, tal como lo expreso más adelante y también expuse en una conferencia en Londres en 1997, que incluyó algunas ideas acerca de la descomposición y destrucción psicológica que ocurre en la esquizofrenia (Fergusson, 1997b). 
En la cuarta carta presenté el psicoanálisis como una mezcla inseparable de autoanálisis y de lo que allí denominé aloanálisis. Es esta mezcla la que considero interminable. Traté de mostrarle de qué manera la regla fundamental es realmente fundamental, tanto durante el aloanálisis como durante el autoanálisis. Finalmente, comencé a describir de qué manera los cambios metapsicológicos que produce el psicoanálisis son, ante todo, consecuencia del intento de cumplir la regla fundamental.

\section{Cambios que producen el psicoanálisis: sus alcances y su marginalidad}

En 1937 usted escribió "the purpose was radically to exhaust the possibilities of illness in them and to bring about a deep-going alteration of their personality". Los cambios en la mente producidos por el psicoanálisis a los que me referí en las cartas anteriores constituyen, de hecho, una alteración de la personalidad: primero, una disminución de la inconsciencia de la represión y de lo reprimido; segundo, cambios en los registros mentales, desde un punto de visita dinámico, topográfico y económico, en la medida en que se van logrando nuevos registros en el sistema Pc-Cs o, si prefiere, en que se va logrando que donde había ello, o superyó, predomine el yo. Le insisto en esto último pues uno de los efectos no buscados que tuvo su teoría estructural fue el de "moralizar" el psicoanálisis. ${ }^{1}$ Se le atribuyó al superyó una posición similar a la del yo, perdiendo de vista su tendencia natural a deshacerse y a ser remplazado por el yo junto con su sentido ético racional. El carácter revolucionario del psicoanálisis reside, por un lado, en la regla fundamental y sus efectos, pero también en el hecho de que las normas sociales que residían en el superyó son ahora asumidas por el yo. Los derivados cambian su dinámica y sus destinos con el cumplimiento de la regla fundamental y el hacer consciente lo dinámicamente inconsciente. Usted esperaba que los derivados disminuyeran o, de lo contrario, no entenderíamos su esperanza de "exhaust the possibilities of illness" (ibíd.); además, tenía la convicción interna agudizada de la existencia de una tópica psíquica real actuante y determinante (Cs, Pcs e Ics, diferenciados de la forma en que funcionan como sistema).

\footnotetext{
${ }^{1}$ Comunicación personal con Tufik Meluk.
} 
También en esta cuarta carta establecí que el psicoanálisis es una mezcla de autoanálisis y aloanálisis, intentando recuperar la legitimidad y la necesidad del primero. La actividad psicológica de un psicoanalizado se vuelve un ciclo interminable de aloanálisis y autoanálisis: aquellos que nunca vuelven a hacer un aloanálisis siempre se mantienen abiertos a esa posibilidad, considerándolo algo que "deberían" hacer, y los que se encuentran en un proceso de aloanálisis siempre esperan poder terminarlo para regresar a su autoanálisis.

Cuando pensamos en la "terminación" del análisis, enfrentamos con frecuencia una cierta confusión de términos y conceptos. Las relaciones y "neurosis de transferencia" entre analistas y analizandos pueden y deben terminar, pero ello no significa que el psicoanálisis termine. Existen procesos analíticos atascados o poco exitosos, pero estos son otro tema. Su énfasis en lo patológico, tal como lo entendimos en 1937, posiblemente contribuyó a pensar que el análisis debería de alguna manera terminar. Sin duda, los aseguradores de salud tienen un interés en que se termine el proceso, aunque buena parte del mismo va a transcurrir en medio de un autoanálisis que no les significa ningún costo. Esto demuestra una vez más la inevitable y hasta razonable marginalidad y distancia entre el psicoanálisis y las instituciones educativas y de salud. Las instituciones de salud, por ejemplo, con dificultad entienden la enorme importancia de promover el análisis de personas mentalmente sanas. En un extremo considero válido el análisis de psicóticos, pero también es válido el psicoanálisis de personas normales, sin que sea necesario que inventemos un diagnóstico para justificar un proceso psicoanalítico en ellos. Es claro que la estructura metapsicológica de los mismos analizandos "normales" cambia de por vida y que experimentan un "deep-going alteration of their personality" (Freud, 1937), para utilizar su expresión. Si el concepto de normalidad no se mantiene, el de la patología tampoco puede perdurar; aunque esta idea también se podría discutir, a pesar de que hoy en día tiende a aceptarse más fácilmente el concepto de patología mental que el de normalidad.

\section{La regla fundamental}

Dado que relaciono los cambios irreversibles en la metapsicología del analizado y el carácter interminable del análisis con la adherencia sincera y decidida al uso de 
la regla fundamental por parte del analista y del analizando, debo precisar cómo opera la metapsicología de dicha regla. Invitemos otra vez a la bruja, tal como usted lo dijo en 1937:

\footnotetext{
'So muss denn doch die Hexe dran!' -the Witch Metapsychology. Without metapsychological speculation and theorizing -I had almost said 'phantasying'- we shall not get another step forward. Unfortunately, here as elsewhere, what our Witch reveals is neither very clear nor very detailed. (Freud, 1937)
}

La bruja sigue siendo indispensable a pesar de sus limitaciones. Estoy de acuerdo con Clifford York cuando sugiere que debemos tratar de desarrollar la metapsicología existente sin apresurarnos a proponer otras nuevas e innecesarias (York, 2001). Entiendo la regla fundamental como el compromiso libre y voluntario por parte del paciente de intentar comunicarle de manera verbal al analista todo el material psíquico que atraviesa por su mente durante la sesión. La regla fundamental es el único componente técnico que pertenece exclusivamente al psicoanálisis. Los demás fenómenos que ocurren en un proceso psicoanalítico (incluida desde luego la transferencia) están de alguna manera presentes en otras terapias psicológicas. Cualquier ciencia comienza desarrollando herramientas que permitan observar aquella porción del mundo material que se quiere estudiar. Uno de sus descubrimientos más brillantes, profesor Freud, fue la regla fundamental, aún más que la transferencia, quizás la segunda herramienta más importante para observar la mente. Usted utilizó primero el método catártico, luego la hipnosis, seguidos por la libre asociación y —-medio desesperado, me imagino-, la presión en la frente del paciente con la intención de invocar material psíquico oculto, hasta que finalmente llegó el gran descubrimiento: la regla fundamental, que es en cierto sentido su opuesto. Hasta donde sé, nadie ha descubierto una técnica mejor para observar la mente consciente e inconsciente.

\section{El psicoanálisis como la ciencia de la consciencia: el "cómo" en vez del "por qué”}

Al comienzo la intención no fue, ni debía haberlo sido, la de llegar a lo inconsciente. Esta idea ha sido una grave equivocación teórica y técnica del psicoanálisis. 
Por el contrario, el psicoanálisis es el estudio más profundo y minucioso que existe del consciente psíquico. La regla fundamental es un mandato consciente que invita al analizando, y al analista a través de su "evenly suspended attention”, a concentrarse en lo consciente, lo cual conlleva a la segunda regla, según Ferenczi, que obliga al analista a ser psicoanalizado (1928). Se llega a lo inconsciente cuando se logra, a través de la reiterada insuficiencia del consciente para explicar el consciente, tal como usted lo describió en su artículo acerca del inconsciente en 1915.

Así, es posible redescubrir el inconsciente una y otra vez aunque, como actitud técnica, debemos estar dispuestos a que encontremos algún día una persona que no tenga inconsciente psíquico. Centrar la técnica en lo consciente también nos ayuda a valorar lo que podamos ir conociendo acerca de "cómo" opera el psiquismo de una persona, sin buscar directamente los "porqués". Al igual que lo inconsciente, los "porqués" surgen sin que jamás vayamos tras ellos directamente. Centrar la técnica analítica en la regla fundamental quiere decir centrarla en lo consciente, cosa muy distinta a centrarla en una búsqueda apresurada de lo inconsciente y los porqués. Como decía un colega: "Lo que hacemos en nuestra práctica es evitar que lo consciente se haga inconsciente". Esto también se aplica al "cambio": aparte del cambio metapsicológico básico, jamás se busca ningún cambio; si llega, llega. Mis inquietudes con respecto a los “cómos", los "porqués” y el "cambio" se exploraron de forma más completa durante mis trabajos en el campo de la auto-rehabilitación acompañada enfocados hacia un mejor entendimiento de las personas diagnosticadas con esquizofrenia (Fergusson, 1997a, 1997b, 1998, 2000, 2002, 2007 y 2008).

El analizando tiene el derecho y el deber de hablar, y es la fuente inicial de todo el conocimiento. Esto constituye la puerta de entrada del psicoanálisis a la ciencia y lo aleja de ser una simple especulación metafísica. La regla exige poner la secuencia de material psíquico en palabras, lo cual va contra la forma en que la mente funciona normalmente. Ninguna otra relación humana, incluyendo otras formas de psicoterapia, pide semejante cosa, y ninguna otra forma de relación toleraría dicha condición. Por lo tanto, no debe sorprendernos que

\footnotetext{
2 Comunicación personal con Carlos Plata.
} 
las personas que nos hemos sometido durante muchos años a dicha práctica tengamos características que nos hacen diferentes. Es lo que permite hablar de una comunidad, casi de una subcultura, de psicoanalizados. Nos volvemos de cierta forma diferentes de por vida y ello en ocasiones nos desune. La gran paradoja, profesor Freud, es que, hasta donde yo sepa, usted nunca tuvo un aloanálisis propiamente dicho y, por consiguiente, no perteneció a dicha comunidad. Usted presintió sus efectos gracias a su propio autoanálisis y a lo que alcanzó a observar durante los aloanálisis de sus pacientes. Suelo pensar que usted hubiera disfrutado mucho de un buen aloanálisis que le exigiera el cumplimiento razonable con la regla fundamental. Su gran tragedia fue no haber encontrado, hasta donde sepamos, un analista que le permitiera sentirse lo suficientemente cómodo como para someterse a la experiencia.

\section{El uso erróneo de la transferencia como sinónimo de la relación analítica}

La regla es fuente tanto de libertad como de obligación, aunque me atrevería a afirmar que, en la práctica, se enfatiza más en la libertad que en la obligación. Lo anterior es especialmente cierto en el análisis llamado ortodoxo, siguiendo el sentido que le dan al término Beate Losher y Peter M. Newton en su libro The Unorthodox Freud (1996). Profesor Freud, no vaya a tener la ingenuidad de pensar que el análisis ortodoxo del que habla dicho libro se refiere al suyo. Todo lo contrario. Se refiere a las técnicas que se desarrollaron después de su muerte y que, en algunos aspectos, poco recuerdan la suya. Este libro muestra también cómo la transferencia y la contratransferencia (transferencia recíproca) pueden o no darse en cada momento de la relación analítica. Esto último solo para informarle que, después de su muerte, los conceptos de transferencia y contratransferencia se empezaron a volver sinónimo de la relación analítica, con lo cual tienden a desaparecer como conceptos: si algo es todo al mismo tiempo, termina no siendo nada (Fergusson, 1986). Igual que con el inconsciente, es preferible suponer que todo está relacionado con la actual relación hasta que se demuestre lo contrario.

Algunos de los cambios metapsicológicos más importantes y duraderos que se dan en la comunidad de psicoanalizados se originan en la separación en dos momentos que inevitablemente surgen durante el cumplimiento con la regla. 
El primero consiste en observar "whatever goes through the mind", y al segundo lo caracterizan las palabras que se utilizan para reportar lo anterior. El primero es un momento involuntario y pasivo, y el segundo, voluntario y activo. Permítame enfatizar una vez más que ambos son eventos conscientes. En el autoanálisis la persona también atraviesa por los dos momentos, con la diferencia de que no está obligada a hacerle un reporte verbal a otra persona, aunque puede y suele hacerlo de forma parcial. Seguramente fue así como surgió la dinámica de su famoso "autoanálisis con Fliess". Este ejercicio modifica la forma en la cual la mente funciona y la forma de valorar nuestro material psicológico.

Paralelo a lo anterior, la dinámica propia del psicoanálisis comienza ante la imposibilidad de cumplir plenamente con esta regla, debido al desfase inevitable que existe entre la cantidad de material psíquico que pasa por la mente y la posibilidad de reportarlo de manera verbal. Su cumplimiento absoluto es, en efecto, imposible, aun sin pensar en las resistencias por motivos que podríamos llamar neurofisiológicos. En nuestra práctica nos interesa su violación más allá de dicha imposibilidad. Lo importante es, entonces, la decisión consciente y voluntaria de cumplirla. Si se viola, lo único que queda claro es que ocurrió una violación. Estamos frente a un ejemplo de la "moral sin sanción ni obligación" de la que hablaba Guyau en su utopía (1978). Es claro que cumplir con la regla puede modificar hasta cierto punto el material psíquico que aparece en la conciencia. La magnitud y la forma en la que esto ocurre constituyen quizás una de las diferencias fundamentales entre el aloanálisis y autoanálisis. Creo que esto es lo que uno de mis colegas ${ }^{3}$ quería expresar al decir que un proceso psicoanalítico solo se completa durante un autoanálisis, después del aloanálisis.

No sobra aclarar que cuando hablo de autoanálisis no me refiero al proceso de elaboración que ocurre entre una sesión de aloanálisis y otra, cuando consciente de la obligación de cumplir en la siguiente sesión. La esencia del autoanálisis consiste en someterse a la obligación de cumplir con la regla fundamental cuando uno está solo. Sin embargo, cuando la regla falla, genera la dinámica de todo el proceso psicoanalítico. Tiende a abrir la consciencia de una manera que eventualmente pone en evidencia los derivados. Bajo la aceptación voluntaria

\footnotetext{
${ }^{3}$ Comunicación personal con Guillermo Ballesteros.
} 
de la regla no existen racionalizaciones, salvo las limitaciones neurofisiológicas, para no cumplirla. La regla obliga al analizando a asumir plena responsabilidad por su propio análisis, mientras coloca simultáneamente al analista en una posición de gran responsabilidad, pues su tarea debe ser la de convertirse en el mejor receptor posible de la regla, de manera que el incumplimiento de la misma por parte del analizando se deba más a sus propias resistencias.

\section{Los analistas como fuente de información}

En términos generales, hemos desaprovechado una fuente valiosa de información para avanzar en la comprensión de diferentes temas psicoanalíticos: la exploración a fondo de las versiones de psicoanalistas acerca de sus procesos de análisis (auto y alo), los cuales, por definición, han debido ser minuciosos. Traté de corregir lo anterior, verificando con ellos algunos aspectos de lo que le he venido planteando, profesor Freud, hasta el momento. Esta verificación se hizo por dos vías: la primera, a través de conversaciones directas individuales o en grupos de estudio; y la segunda, un tanto indirecta, a través de lo que he observado analizando psicoanalistas en lo que llamamos sus "retomas". Muchas veces uno de los motivos conscientes que tienen para volver a un aloanálisis se relaciona con una convicción profunda de no haber cumplido razonablemente con la regla fundamental en sus análisis anteriores, sumado a la sensación, correcta o no, de que sus analistas no privilegiaban la regla fundamental como eje técnico. La mayor parte de ellos han avanzado en su autoanálisis, pero piensan que deben iniciar un nuevo aloanálisis basado en el cumplimiento de la regla fundamental. Típicamente identifican dos motivos por haber "retomado" aloanálisis: primero, un reconocimiento de mi insistencia en la regla fundamental; y segundo — siempre muy sorpresivo para mí-, la seguridad que les brinda mi experiencia con las personas diagnosticadas con psicosis y esquizofrenia.

Quizás es este el momento para resaltar que entre los psicoanalistas, por sorpresa, existe la percepción de que no estamos cumpliendo razonablemente bien con nuestra obligación de adherir a la regla, y que son pocos los analistas y analizandos que centran su técnica en ella. A medida que aumenta la convicción interior del analista acerca de la importancia de la regla, nos fortalecemos como analistas y realizamos cambios interiores que de forma indirecta crean en los 
analizandos un terreno más propicio para cumplirla. Es decir, la atención libremente flotante es el resultado de cambios profundos en el funcionamiento mental del analista, producto del psicoanálisis interminable en el que por definición permanecerán de por vida y en cada momento de cada sesión (Fergusson, 1994).

\section{Las consecuencias de vivir bajo el reglamento fundamental}

Son varias las razones por las que muchos analistas no vuelven a aloanalizarse, y deben ser parecidas a las que le impidieron a usted hacerlo. Algunos analistas se aloanalizan, medio a la fuerza, durante la formación y nunca más, incapaces, al parecer, de encontrar el analista apropiado. Un motivo muy poderoso que puede existir para evitar el análisis, especialmente el centrado en la regla fundamental, consiste en que tememos la pérdida de libertad que implica el saber que lo que uno haga, sienta o piense en la vida, y luego se le ocurra en el diván, debe ser expresado verbalmente. Esta resistencia es más potente de lo que hemos querido aceptar y constituye uno de los principales desafíos técnicos hoy en día: cómo desarrollar en la persona que se aloanaliza habilidades que permitan llevar a cabo su vida sin que los obligatorios reportes verbales vuelvan su vida un tanto artificial. El analista puede ayudar a desarrollar estas habilidades en sus pacientes al confesar su sincera y profunda ignorancia de cómo deben disponer de sus vidas (Fergusson, 1997 y 2002).

\section{Algunos desarrollos en el movimiento psicoanalítico}

Quisiera actualizarlo con respecto a algunos desarrollos recientes en el movimiento psicoanalítico, incluyendo algunos eventos relacionados con mi vida profesional. He explorado diferentes teorías y alternativas terapéuticas, intentando encontrarle un lugar filosófico y político al psicoanálisis. Intenté, al igual que algunos pensadores de la llamada Escuela de Frankfurt, integrar su pensamiento con el materialismo histórico y dialéctico. Los intentos de esta naturaleza fueron múltiples en Suramérica, donde se ha desarrollado la mayor parte de mi vida profesional, sobre todo durante las décadas del sesenta y setenta del siglo XX. En un momento me quise desprender un poco del ambiente tenso que se vive a ratos en algunas sociedades e institutos psicoanalíticos (sé que usted alcanzó a ser testigo de esto durante su vida, pero después de su muerte el asunto empeoró). 
Hasta me pregunto en ocasiones si no fue usted el que involuntariamente dio origen a dicha tensión con iniciativas como su famoso "Comité Secreto". De hecho, fue hace muy poco en realidad que logré una visión más clara de ciertas cosas, luego de reexaminar en detalle el proceso histórico de los psicoanalistas londinenses. Dudo de que usted fuera capaz de imaginar las consecuencias de las llamadas “controversias londinenses" - aquellas diferencias teóricas entre su hija Ana y Melanie Klein - no solamente en el Reino Unido sino, curiosamente, en todo el mundo, sobre todo en Suramérica. En la actualidad, existen múltiples minicomités secretos y el ambiente que crean, mi querido profesor, es bastante aburridor y sin duda ha hecho daño al movimiento psicoanalítico. Creo que algunas personas que se entusiasmaron con sus ideas se han alejado por ese motivo del psicoanálisis.

Como habrá notado, algunos de mis planteamientos fueron influenciados por mi trabajo psicoanalítico con personas diagnosticadas con esquizofrenia. En efecto, desarrollé un enfoque denominado auto-rehabilitación acompañada (inicialmente, autoanálisis acompañado), el cual ha sido aplicado a través del Instituto de Auto-rehabilitación Acompañada, tanto en Colombia como en los Estados Unidos (Díaz, Fergusson y Strauss, 2004). Este trabajo se desarrolló principalmente en Fungrata, lo que algunos llamarían una comunidad terapéutica. Nuestra intención siempre fue la de utilizar a "la bruja" para entender la esquizofrenia y la experiencia parecía, entre otras cosas, una excelente oportunidad para poner en práctica la integración de sus ideas con los planteamientos sociales. Algo de lo que hicimos recuerda las famosas free clinics que usted tanto defendió a partir de 1918 en el Congreso de Budapest.

Nuestra experiencia también recuerda lo que trataron de hacer Ernst Simmel, Otto Fenichel, Wilhelm Reich, Grete Bibring y otros, aunque debo confesar que me enteré de los detalles de dichas experiencias hace muy poco, gracias a un libro de Elizabeth Danto titulado Freud's Free Clinics (2005), una investigación minuciosa sobre los primeros años del desarrollo del psicoanálisis. Gracias a este magnífico libro hemos entendido cada vez mejor las dinámicas experimentadas por la segunda generación de analistas (Jacoby, 1983), similares a las que surgieron al implementar nuestro programa en Suramérica y los Estados Unidos. Sería bueno rescatar la enorme fuerza que tuvo esta segunda 
relativamente olvidada generación. El psicoanálisis nació en Europa Central, sobrevivió en Estados Unidos y en el Reino Unido en la época posnazi, y yo creo que llegará a su madurez y recuperará su valor humanístico y social, y su energía, en Suramérica. La doctora Danto me hizo recientemente una interesante reflexión, preguntándose cómo habría sido la historia del desarrollo del psicoanálisis en el Reino Unido si Fenichel se hubiese radicado en Londres. ${ }^{4}$ Me pregunto qué opinaría usted al respecto. Siempre pensé que el psicoanálisis no podría ser ni podrá subsistir si se excluyen sectores importantes de la población por motivos de su condición socioeconómica o de la severidad de su patología. A pesar de algunas dudas que rondan en los corredores psicoanalíticos, las investigaciones de la doctora Danto y las de Jacoby confirman que usted pensaba igual. Usted veía claramente la enorme responsabilidad social del psicoanálisis. El libro de Beate Lohser y Peter M. Newton (1996) citado anteriormente, y otro denominado Revolution in Mind escrito por George Makari (2008), han aprovechado la claridad que en ocasiones da el paso del tiempo para aportar una visión más real de los orígenes del psicoanálisis, de su pensamiento teórico e, inclusive, de su metodología.

Incluyo en esta especie de "actualización bibliográfica" un libro titulado Medical Muses escrito por Asti Hustvedt (2011) dado que uno de los golpes más grandes que ha recibido el psicoanálisis en la actualidad consiste en que ha ido desapareciendo el diagnostico de histeria. Se ha puesto de moda una serie de diagnósticos tales como trastornos de pánico, trastornos de alimentación (bulimia y anorexia), fatiga crónica, episodios disociativos y muchos otros que con frecuencia no son más que manifestaciones de la misma y muy grave histeria de siempre. Esto tiene que ver con el hecho de que los síntomas de algunos de estos trastornos aparecieron al mismo tiempo que los medicamentos utilizados en su tratamiento: los diagnósticos se lanzan al mercado a tiempo con las curas. El libro de la doctora Hustvedt explica este fenómeno y examina la paulatina negación de la existencia de la histeria como condición psicológica. Aprovecho para comentarle también, profesor Freud, que hoy en día el mundo se está convirtiendo en lo que en otro trabajo llamé un "asilo químico" (Fergusson, 1988b): grandes

\footnotetext{
${ }^{4}$ Comunicación personal con E. Danto.
} 
porcentajes de la población toman alguna forma de medicamento psiquiátrico basado en indicadores científicamente cuestionables.

\section{El psicoanálisis en las Américas}

No quisiera terminar esta carta sin referirme a algo que ha pasado en los Estados Unidos, donde parte de mi trabajo se ha desarrollado. Con frecuencia recuerdo la ambivalencia, por decir lo menos, que usted sentía con respecto al futuro del psicoanálisis en ese país. Ocurrió que después de presentar el modelo de auto-rehabilitación acompañada en el Hospital Psiquiátrico de Saint Elizabeth en Washington (Fergusson, 2001), recibimos una propuesta muy tentadora de parte de un grupo de personas que deseaban acogerlo y masificar su aplicación. Decidí no aceptar la oferta pues me parecía que en la forma en la que pensaban aplicarlo perdería su esencia. Poco tiempo después, un abogado de Nuevo México me contó una historia que justificaba en parte nuestros temores: la de Starbucks. Esta cadena se había inspirado en los "cafés parisinos", pero al masificarlos en Estados Unidos los cafés habían perdido su esencia. Starbucks y los cafés parisinos son cosas muy diferentes, me explicaba el abogado. ¿Sería acaso algo parecido lo que usted temía que pasara con el psicoanálisis en Estados Unidos? Sin embargo, sus temores con respecto al futuro del psicoanálisis en ese país no fueron del todo justificados; el aporte estadounidense al psicoanálisis es innegable. Permítame un solo ejemplo: durante muchos años luchamos dentro de la National Association for the Advancement of Psychoanalysis (NAAP) por volver realidad uno de sus sueños más deseados: hacer que el psicoanálisis fuera reconocido como una profesión independiente. Acuérdese de sus ideas acerca del análisis por no-profesionales y su apoyo a Teodoro Reik. La lucha ha sido exitosa y ya en los estados de Vermont y Nueva York se puede obtener licencia como psicoanalista, igual que cualquier profesión independiente. Sé que usted se alegrará con esta noticia. Por fin estamos a punto de lograr que reconozcan que para ser psicoanalista simplemente hay que "ser psicoanalista".

Usted temía que el psicoanálisis se convirtiera en la "sirvienta" de la psiquiatría en Estados Unidos. En eso tuvo algo de razón, pero debo aclararle que lo mismo ocurrió en todas partes del mundo, hasta en su amada Viena y en su respetado Reino Unido. Actualmente, la situación ha cambiado. Podemos decir 
que la "sirvienta" fue despedida del todo la psiquiatría, una pérdida que duele más a la psiquiatría que al psicoanálisis. Y aunque muchos de mis colegas psicoanalistas no comparten la idea, a mi juicio, se han forzado un poco las "validaciones" y "equivalencias" que las neurociencias parecen haber otorgado a ciertos conceptos psicoanalíticos, buscando quizás un nuevo rencuentro con la medicina y la biología. Ello, a mi modo de ver, constituye un error metodológico; los conceptos psicoanalíticos básicos de los que hablan las neurociencias son cosas diferentes. Solo nuestra bruja nos puede ayudar en dichos momentos de confusión. Con ella podemos reafirmar nuestros puntos de vista económicos y dinámicos, sin tener que utilizar teorías prestadas hasta cierto punto para convencernos a nosotros mismos y a los demás de la veracidad y del carácter científico de los hallazgos psicoanalíticos. Sin embargo, en esto también a usted le cabe una enorme responsabilidad: la inseguridad teórica con respecto a la metapsicología psicoanalítica la inició usted sin quererlo cuando dijo que algunos de sus hallazgos podrían ser comprobados químicamente algún día. A mi juicio, ello no puede ni tiene por qué ocurrir jamás, mi estimado profesor. Sería desconocer que el mundo material se organiza en diferentes niveles de integración que no pueden reducirse a otros niveles. Eso es tan impensable como aspirar a que los movimientos sociales se entendieran como movimientos químicos. El reduccionismo es arriesgado. Quizás estoy siendo injusto y ni usted se imaginó que esta frase nos traería tantos dolores metodológicos de cabeza. Tampoco es culpa suya que le hayan idealizado tanto, ni que se llegara a pensar que usted no cometía errores teóricos ni políticos. Su genial aporte consistió precisamente en haber podido rescatar el concepto de lo psíquico para la ciencia, pero para la ciencia psicológica y no tanto para la biológica ni para las ciencias sociales. Esta claridad hace que, desde la perspectiva metodológica, la relación entre el psicoanálisis y las otras disciplinas se vuelva mucho más productiva.

\section{Bibliografía}

Arcila, G. (1986). El olvido de la regla fundamental. Revista de la Sociedad Colombiana de Psicoanálisis, 9(1).

Danto, E. (2005). Freud's Free Clinics. Psychoanalysis and Social Justice (1918-1936). New York: Columbia University Press. 
Díaz, E.; Fergusson, A.; \& Strauss, J.S. (2004). Innovative Care for the Homeless Mentally Ill in Bogotá, Colombia. In Jenkins, J.H. and Barrett, R.J. (eds.), Schizophrenia, Culture, and Subjectivity. The Edge of Experience. Cambridge: Cambridge University Press.

Fergusson, A. (1985). Sobre la inconsciencia de lo represor. Carta No. 1. Revista de la Sociedad Colombiana de Psicoanálisis, 10(2), 145-170.

Fergusson, A. (1986). La transferencia y el preconsciente dinámico en la relación psicoanalítica. Revista de la Sociedad Colombiana de Psicoanálisis, 11(1), 145-170.

Fergusson, A. (1987). “Sobre los derivados y los registros mentales. Carta imaginaria No. 2". Revista de la Sociedad Colombiana de Psicoanálisis, 12(2), 361-371.

Fergusson, A. (1988a). Sobre la necesidad de diferenciar el punto de vista sistémico del punto de vista tópico. Carta imaginaria No. 3. Revista de la Sociedad Colombiana de Psicoanálisis, 13(3), 405-412.

Fergusson, A. (1988b). The Chemical Asylum, paper presented at the meeting of the Medical Staff Executive Committee. Bogotá: Fungrata.

Fergusson, A. (1989). Autopsicoanálisis. Carta Imaginaria No. 4. Revista de la Sociedad Colombiana de Psicoanálisis, 14(2), 229-249.

Fergusson, A. (1992). La estupidez. Otra vía regia al inconsciente psíquico. Revista de la Sociedad Colombiana de Psicoanálisis, 17(1), 22-33.

Fergusson, A. (1994). Qué significa estar en forma para psicoanalizar. Revista de la Sociedad Colombiana de Psicoanálisis, 19(1).

Fergusson, A. (1997a). La técnica del autoanálisis acompañado y la teoría de la psicosis entendida como destrucción y descomposición psicológica. Revista de la Sociedad Colombiana de Psicoanálisis, 22(2), 169-184.

Fergusson, A. (1997b). The technique of Accompanied Autoanalysis and the Theory of Psychosis as Psychological Destruction and Decomposition, 12th International Symposium for the Psychotherapy of Schizophrenia (ISPS), London.

Fergusson, A. (1998). La normalidad a la luz de la locura. En Pérez, A. (ed.), Monografías, foros y debates clinicos. Bogotá: Universidad de los Andes.

Fergusson, A. (2000). Accompanied autoanalysis: An Empathic Approach. Ethical Human Sciences and Services: an International Journal of Critical Inquiry, 2(1), 9-20. 
Fergusson, A. (2001). On Accompanied Self-Rehabilitation, a paper presented at the meeting of the Medical Staff Executive Committee, St. Elizabeth Hospital, Washington DC.

Fergusson, A. (2002). Accompanied Autoanalysis: An Empathic Approach to Helping Deeply Disturbed Persons. In Breggin, R.; Breggin, G., \& Bemak, F. (eds.), Dimensions of Empathic Therapy. New York: Springer.

Fergusson, A. (2007). Social Sanctions in Mental Illness, paper presented at the meeting of the Medical Staff Executive Committee. Bogotá: Fungrata.

Fergusson, A. (in collaboration with A. Realpe). (2008). "Consent, Accountability and the Future of Therapeutic Communities in the Light of Accompanied Selfrehabilitation. The Chemical Asylum and the Right to Be Socially Sanctioned”. In Gale, J.; Realpe, A., \& Pedriali, E. (eds.), Therapeutic Communities for Psychosis. Philosophy, History and Clinical Practice. New York: Routledge.

Freud, S. (1903-1904). The Psychoanalytic Procedure. SE, 7, pp. 247-254.

Freud, S. (1912). Recommendations to Physicians Practising Psychoanalysis. SE, 12, 109-120.

Freud, S. (1913). On beginning the treatment (Further recommendations on technique of psycho-analysis I). SE, 12, pp. 1-144.

Freud, S. (1914). Remembering, repeating and working-through (Further recommendations on the technique of psycho-analysis II). SE, 12, 145-156.

Freud, S. (1915). The Unconscious, Collected Papers. Vol. IV. London: Hogart Press \& The Institute of Psychoanalysis.

Freud, S. (1977). The Ego And The Id [1923]. London: The Hogarth Press.

Guyau,J.M. (1978). Esbozo de una moral sin obligación ni sanción. Madrid: Biblioteca Jucar. Hustvedt, A. (2011). Medical Muses. Hysteria in Nineteenth-Century Paris. New York: W. W. Norton \& Company.

Jacoby, R. (1983). The Repression of Psychoanalysis. Otto Fenichel and the Political Freudians, New York, The University of Chicago Press.

Lohser, B. and Newton, P.M. (1996). The Unorthodox Freud. The View from the Couch, New York, The Gilford.

Makari, G. (2008). Revolution in Mind. The Creation of Psychoanalysis. New York: Harper Perennial. 
York, C. (2001). The Unconscious: Past, Present, and Future. In Steiner, R., \& Johns, J. (eds.), Within Time \& Beyond Time. A Festschrift for Pearl King. New York: Karnac, pp. 25-38. 